Applied Remote Sensing

\title{
In-air spectral signatures of the Baltic Sea macrophytes and their statistical separability
}

Jonne Kotta

Kalle Remm

Ele Vahtmäe

Tiit Kutser

Helen Orav-Kotta 


\title{
In-air spectral signatures of the Baltic Sea macrophytes and their statistical separability
}

\author{
Jonne Kotta, ${ }^{\text {a,* }}$ Kalle Remm, ${ }^{\mathrm{b}}$ Ele Vahtmäe, ${ }^{\mathrm{a}}$ Tiit Kutser, ${ }^{\mathrm{a}}$ and \\ Helen Orav-Kotta ${ }^{a}$ \\ ${ }^{a}$ University of Tartu, Estonian Marine Institute, Mäealuse 14, 12618 Tallinn, Estonia \\ ${ }^{\mathrm{b}}$ University of Tartu, Institute of Ecology and Earth Sciences, Vanemuise 46, \\ 51014 Tartu, Estonia
}

\begin{abstract}
Many macroalgal species potentially have distinctive spectral signatures detectable using remote sensing. In order to map the spatial distribution of these species, their spectral properties have to be quantified and statistical differences between species need to be assessed. In the present study, we collected a spectral library of the key benthic macrophyte species in the Baltic Sea area and presented the methodology that allows quantifying statistical differences between their reflectance spectra. The results indicate that three broad groups of algaegreen, brown, and red algae — can be separated based on their optical signatures. In general, the between-species differences are too small to allow easy recognition of benthic algae based on their untransformed reflectance spectra. However, the distinctness of the studied species and taxa improves if standardized reflectance values are used. The best indicative spectral range was at 530 to $570 \mathrm{~nm}$ for the separation of species and of larger taxonomic units. (C) The Authors. Published by SPIE under a Creative Commons Attribution 3.0 Unported License. Distribution or reproduction of this work in whole or in part requires full attribution of the original publication, including its DOI. [DOI: 10.1117/1.JRS.8.083634]
\end{abstract}

Keywords: Baltic Sea; benthic habitat mapping; benthic macrophytes; spectral library.

Paper 13503 received Dec. 3, 2013; revised manuscript received Apr. 8, 2014; accepted for publication Apr. 14, 2014; published online May 9, 2014.

\section{Introduction}

Marine macrophyte communities have high ecological and economic importance. They form extensive habitats in near-coastal zones and are among the most productive habitats worldwide. Consequently, they provide a range of ecological functions, such as protecting coastlines, stabilizing sediments, attenuating waves, filtering land-derived nutrients, and binding carbon, just to name a few. Nowadays, the patterns of species composition of marine macrophytes are used to assess the state of coastal marine environments in sensu according to the EU Water Framework Directive and the EU Marine Strategy Framework Directive. Although the Marine Strategy Framework Directive require a seamless quantification of the cover of macrophyte beds over a range of seascapes, to date, the vast majority of studies have been performed on limited spatial scales, i.e., the size of sampling units remained small and vast areas between grains were left unstudied. ${ }^{1,2}$ Therefore, there is a strong need for methods that allow collecting qualitative and quantitative information about these shallow-water benthic habitats over large sea areas.

The use of remote sensing for improving ecological understanding, monitoring, and managing of marine coastal areas has certain advantages: the method permits synoptic mapping of large areas, allows mapping of inaccessible zones, and is often more cost-effective than conventional methods, e.g., diving and grab sampling. ${ }^{3,4}$ Many macrophyte species potentially have distinctive spectral signatures detectable using remote sensing. In order to map the spatial distribution of these species, their spectral properties have to be quantified.

*Address all correspondence to: Jonne Kotta, E-mail: jonne@sea.ee 
A basic assumption of mapping by remote sensing is that the features of interest in an image reflect or emit light energy in different and often unique ways. ${ }^{5}$ Thus, only the spectrally different features can be mapped. The spectral signatures of submerged benthic vegetation are principally determined by their pigment composition. Earlier studies have demonstrated spectral dissimilarities between the three major groups of macroalgae - the green, brown, and red algae ${ }^{6-9}$ All these macroalgae contain chlorophyll a, but differ in the presence of other chlorophylls and accessory pigments, such as carotenoids (carotenes, xanthophylls) and phycobilins (phycocyanin, phycoerythrin). ${ }^{10}$ Nevertheless, it is also plausible that within these broad taxonomic groups, many macroalgal species have unique pigment combinations.

Spectral signatures are one of the most promising features of coastal aquatic systems that can be exploited for both science and management applications of remote sensing. ${ }^{11-13}$ In such a spectral library approach, remote sensing reflectance spectra (Rrs) of individual pixels in the images are compared to measured/simulated Rrs spectra. ${ }^{12,14}$ Creating a modeled spectral library requires measured values of bottom reflectance and data about inherent optical water properties. ${ }^{14}$ The advantages of spectral library approach are that there is no need of extensive field surveys ${ }^{12}$ when the optical properties of benthic habitats are determined and possible variability in optical water properties can be estimated. There is no need to collect in situ data simultaneously at the time of image acquisition; it is easy to apply the methodology on data from different sensors as the spectral library can be recalculated for spectral bands of each sensor. There is also no need of depth data as the method resolves both depth and benthic habitat type information simultaneously. However, high-quality atmospheric correction is required to classify a remote sensing image using a modeled spectral library.

The spectral library approach requires a quantification of the range of signatures expected for any species under natural conditions. ${ }^{14-17}$ In nature, however, there exists a considerable variation in pigment composition and quantity among broad taxonomic groups and even within species. For example, the brown algae may range in color from beige to almost black. ${ }^{18}$ Such differences may be related to species-specific character of pigment composition but also induced by environmental factors, such as light, nutrients, and water flow. ${ }^{10}$ Moreover, the overall spectral appearance of an alga cannot necessarily be inferred based only on the knowledge of the pigments present. The morphology, thickness of thalli, and cellular architecture affect the relationship between pigment densities and absorption spectra ${ }^{19-21}$ and, consequently, affect the formation of reflectance spectrum. At the other extreme, however, some authors have questioned whether spectral signatures of individual plants are unique at all. ${ }^{15}$ This plethora of diversity makes it very challenging to establish the typical ranges of reflectance spectra of macrophyte species and assess significant differences among groups. To date, spectral signatures of the ecological end-members have been published for some corals, macroalgae, and seagrasses. ${ }^{9} 18,22,23-25$ Nevertheless, these studies mainly concentrated on species growing in ocean waters. Moreover, very few did account for the variability of spectral signal within and between species (e.g., Ref. 22). To assess a potential of remote sensing methods for monitoring macrophyte beds, however, ranges of spectral signal of macrophyte need to be quantified, and spectral regions that consistently allow discrimination of species or taxa need to be defined.

The development of tools that allow distinguishing the reflectance spectra of different species is often complicated by nonstandardness. Such variability largely degrades the performance of any image processing tool. Standardizing may refer to many types of ratios, but usually this is done by subtracting the mean of the particular spectrum from the raw reflectance values and dividing by the standard deviation of the same raw reflectance values. Usually standardization refers to a preprocessing step that aims to improve reflectance constancy by realigning intensity distributions of images. However, a standardization algorithm can as well be applied for reflectance spectra, i.e., instead of preprocessing pixels of images, reflectance values at different wavelengths are corrected by the properties of spectral signature over the whole spectral range.

Based on the above, the objectives of this study were (1) to quantify the spectral properties and variability of the key benthic macrophyte species in the Baltic Sea area; (2) to demonstrate a methodology that allows quantification of statistical differences between the reflectance spectra of macrophyte species and broad taxa by utilizing both nonstandardized and standardized spectra; and (3) to define which spectral regions contribute most to the observed statistical differences. 


\section{Material and Methods}

\subsection{Study Area}

The Baltic Sea is an intracontinental shallow marine environment under a strong influence of human activities and terrestrial material. Large discharge from rivers, limited exchange with marine waters of the North Sea, and extensive shallow areas significantly influence the optical properties of the Baltic Sea. ${ }^{26}$

The Baltic Sea hosts all three main groups of macroalgae (green, brown, and red macroalgae) as well as higher plants. In this study, an array of macroalgae and higher plant species were collected from the Estonian and Swedish waters (Fig. 1). The Vilsandi National Park is located in the western coast of Saaremaa Island and it encompasses $~ 160$ islands and islets of different sizes. Most of the area is $<5 \mathrm{~m}$ deep although in a few locations water depth reaches $15 \mathrm{~m}$. Haapsalu Bay extends deeply into the land in the western part of Estonia. The bay is relatively shallow with an average depth of 1.5 to $2 \mathrm{~m}$ and a maximum of $5 \mathrm{~m}$. Vormsi Island is located west of the Estonian mainland. Most of the study areas were $<5 \mathrm{~m}$ deep. The island has extensive shallows in the southern parts and steep and more exposed coasts in its northern parts. Gräsö Island and the St. Anna archipelago are characterized by thousands of islets and bays. Water is generally $>10 \mathrm{~m}$ deep, i.e., the bottom signal is not detectable by remote sensing sensors. Shallow areas occur only near coast and in small bays and channels between islets.

\subsection{Field Survey}

Altogether 531 taxa of benthic vegetation have been found in the Baltic Sea. ${ }^{27}$ It would be excessively labor-intensive to collect reflectance spectra for each of these species. ${ }^{28}$ Moreover, such a task would not be rational since a large number of taxa are rare, hidden in crevices, or spatially imbricate over a few square centimeters. ${ }^{24}$ Moreover, due to similar pigmentation, the reflectance spectra are likely similar for many of these species. Therefore, only the key macroalgae and higher plants were collected for reflectance measurement. The samples included the green algae Cladophora glomerata, Ulva intestinalis, Chara spp., Monostroma balticum; the higher plants Potamogeton pectinatus, Myriophyllum spicatum, Zannichellia palustris; the red algae Ceramium tenuicorne, Furcellaria lumbricalis, Polysiphonia fucoides; and the brown algae Fucus vesiculosus, Pilayella littoralis, Chorda filum, and Dictyosiphon foeniculaceus (Fig. 2). In addition, reflectance spectra of bare sand, pebble, limestone, and silt were measured on different beaches.

Water molecules absorb light strongly in red to near-infrared part of the spectrum, i.e., in the part of spectrum where the main differences between different benthic species occur. ${ }^{29}$ Just a few centimeters of water between the sample and the sensor affect the measured reflectance significantly. Determining the accurate distance between the sample and sensor is not practically

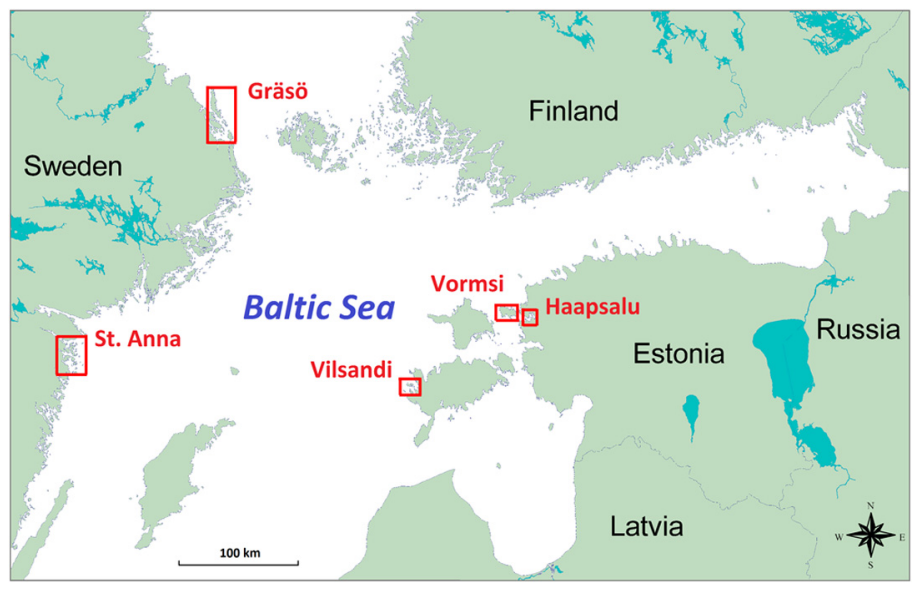

Fig. 1 Macrophyte sampling sites in the Baltic Sea. 


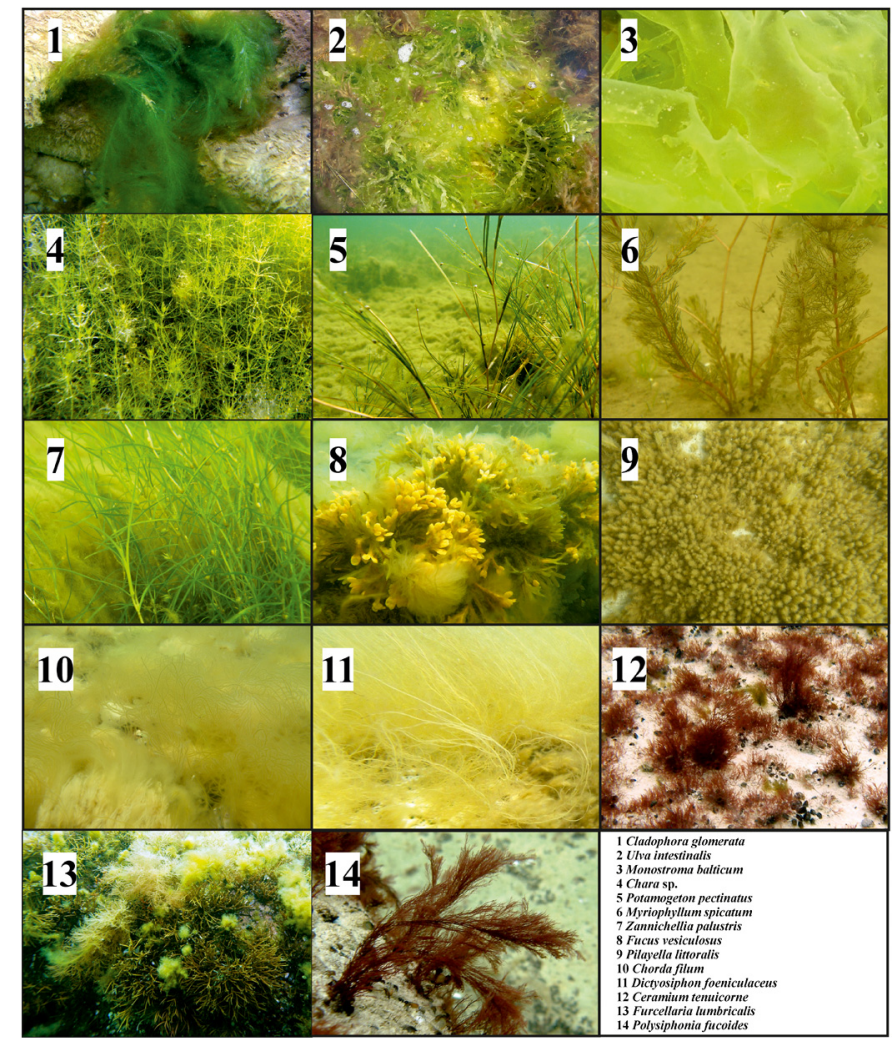

Fig. 2 Still photographs of the studied macrophyte species.

possible during in situ measurements as the water depth, where the measurements have to be carried out, varies between a few centimeters to $\sim 10 \mathrm{~m}$ in the Baltic Sea. Therefore, obtaining the true reflectance of different algae and plants without any impact of water column by means of in situ measurements is practically impossible. Nevertheless, unlike terrestrial vegetation, ${ }^{30,31}$ leaf orientation and canopy geometry are not coupled with the reflectance spectra of aquatic vegetation. Such specific characteristic of macrophytes is an unavoidable consequence of the evergoing mobility of aquatic organisms under the wave exposure. Our long experience in carrying out reflectance measurements in shallow waters suggests that differences in the geometry of canopy do not practically change reflectance spectra, and variation in the canopy properties only marginally contributes to the absolute reflectance values. These changes are likely smaller than the potential uncertainties due to unrecorded distance between the sample and the sensor. Our pilot study also indicated that only slight changes in true reflectance are expected if the macrophytes are removed from water (Fig. 3).

Due to the above-mentioned considerations, macrophytes were taken out from the water, placed on a black plastic bag as piles, and then their reflectance spectra were immediately measured with Ramses hyperspectral radiometers, built by TriOS GmbH (Germany). The macrophytes were kept wet during the measurements. The plastic was mainly used to minimize signal from the adjacent environment. However, the measurements were done in a way that no plastic was seen by the sensor. Five to ten individual spectra were measured for each specimen. The measurements were performed over the entire plants and not only over the blades of the plants in order to cover possible spectral variability within each specimen. Measurements were conducted in the visible and near-infrared range of the spectrum (350 to $900 \mathrm{~nm}$ ) with 3-nm spectral interval. Downwelling light was measured by irradiance sensor and upwelling light by radiance sensor above the sample. In most cases, we used a standard Trios cage while some measurements were carried out holding upwelling radiance sensor by hand. This was needed in order to be able to measure reflectance of different parts of specimens that had more complex canopy structure and visible differences between different parts of the canopy (for example, in the case of Fucus vesiculosus). In order to determine the reflectance spectra of each sample, the upwelling radiance $(\mathrm{Lu})$ was divided by the downwelling irradiance (Ed). 
Kotta et al.: In-air spectral signatures of the Baltic Sea macrophytes and their statistical separability
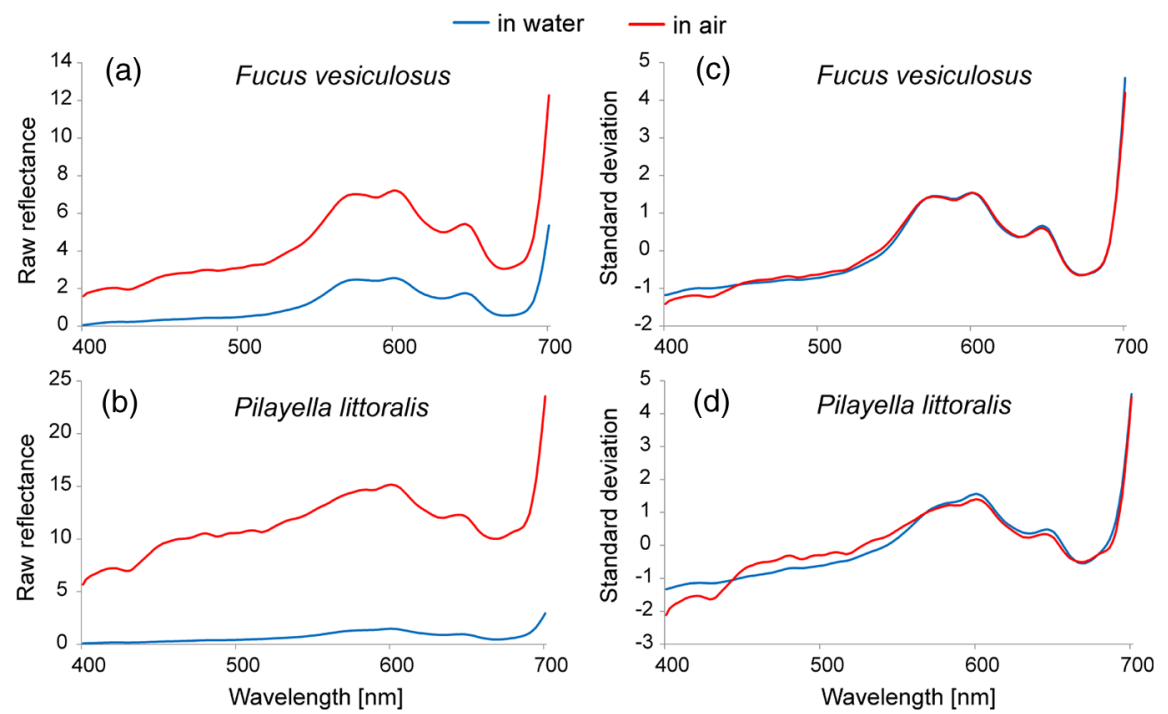

Fig. 3 A comparison of raw (a, b) and standardized spectra (c, d) of Fucus vesiculosus (a, c) and Pilayella littoralis (b, d) in water and in air. The standardization was done by subtracting the mean of the particular spectrum from the raw reflectance values and dividing by the standard deviation of the same spectrum.

\subsection{Statistical Methods}

Five to 10 reflectance spectra were measured of each individual specimen. Up to six different specimens were sampled from each species (Table 1). The individual spectra were averaged to get a reflectance spectrum representing each individual. Then all individual spectra were separately standardized by subtracting the mean of values at all measured wavelengths in the same spectral signature from the averaged individual spectral values and dividing the difference by the

Table 1 The number of specimen and the total number of spectra measured for each plant species.

\begin{tabular}{|c|c|c|c|}
\hline Broad taxa & Species & Number of specimens & Total spectra \\
\hline Brown algae & Chorda filum & 1 & 10 \\
\hline Brown algae & Dictyosiphon foeniculaceus & 1 & 10 \\
\hline Brown algae & Fucus vesiculosus & 5 & 45 \\
\hline Brown algae & Pilayella littoralis & 3 & 30 \\
\hline Green algae & Chara aspera & 6 & 40 \\
\hline Green algae & Cladophora glomerata & 4 & 30 \\
\hline Green algae & Monostroma balticum & 1 & 10 \\
\hline Green algae & Ulva intestinalis & 2 & 15 \\
\hline Higher plants & Myriophyllum spicatum & 2 & 15 \\
\hline Higher plants & Potamogeton pectinatus & 2 & 15 \\
\hline Higher plants & Zannihellia palustris & 1 & 10 \\
\hline Red algae & Ceramium tenuicorne & 4 & 40 \\
\hline Red algae & Furcellaria Iumbricalis & 1 & 10 \\
\hline Red algae & Polysiphonia fucoides & 1 & 10 \\
\hline
\end{tabular}


standard deviation of values in the same spectral signature. Standardization is a common procedure in data processing aimed to make distributions of values comparable. The distribution, in this case, is formed by reflectance values at different wavelengths. The reflectance values were standardized separately for each plant individual. The mean value of standardized spectra is equal to zero, and the standardized reflectance intensity is presented in terms of standard deviations of the raw values. Thus, standardization of reflectance values emphasizes the relative differences in spectral variability. It is important to stress that we did not transform an image of plants but the averaged spectral signature of a macrophyte individual.

A perfect discrimination between categories can easily be obtained from small samples even by chance. Therefore, the overall distinction significance between multiple groups was tested by the Kruskal-Wallis test and pairwise difference of the broader taxa by the two-tailed MannWhitney $\mathrm{U}$ test ${ }^{32,33}$ both using an online calculator. ${ }^{34}$ The Kruskal-Wallis test is a nonparametric equivalent of the one-way analysis of variance for testing independence of more than two samples. It was applied on the broad taxonomic units (red, brown, and green algae and higher plants) as well as on the species level, separately for every spectral interval using raw and standardized spectral values. The $\mathrm{U}$ test is designed for comparison of the median values from two samples.

Both the Kruskal-Wallis test and $U$ test assess a statistical significance of the difference between the groups-how likely is it that the groups of values are merely random samples from the same distribution. These statistical tests do not measure how clear or fuzzy the boundaries between distributions of values are, and where is the best-separating distinction line between the groups. Therefore, for spectral regions where the samples of taxonomic groups were different at $p<0.05$, the optimal separating boundary between the taxa was calculated using a simple iterative search relying on the Hanssen-Kuipers Skill Score-also called True Skill Statistic (TSS) - as the objective function. ${ }^{35}$ The TSS value is calculated as the proportion of true results in one category (T1) plus proportion of true results in the other category (T2) minus one.

$$
\mathrm{TSS}=\mathrm{T} 1+\mathrm{T} 2-1
$$

The range of possible TSS values is $+1 \ldots-1$, zero being the expected value in case of random decisions. The TSS is favorable as it does not depend on the proportion of categories. ${ }^{36,37}$

In order to find reflectance values, which enable separating plant taxa with a minimum proportion of false results, an iterative search algorithm was designed. As the first step, median values of the samples are calculated according to this algorithm. The algorithm is applicable for any two sets of values. In this application, a sample is formed by reflectance values of a certain wavelength measured from objects of one macrophyte taxon, and the other sample includes reflectance values of the same wavelength measured from objects of another macrophyte taxon.

Then, the optimal boundary location is searched between the medians by placing a tentative boundary at the midpoint between a value from one sample and a value from the other sample. Then true and false recognition results are counted separately for both samples given this boundary location imposed upon the data. The optimal boundary location is where the mean proportion of false classification results in both categories is minimal. Such an exhaustive robust search does not depend on the distribution of values in samples and yields optimal results also in case of strongly asymmetrical distribution of values in one of the samples.

Pseudocode of the boundary search algorithm is as follows. The full code is freely available from the above-mentioned online calculator.

1. Sort both samples in ascending order of values.

2. If the first value of one sample is larger than the last of the other, then the optimal boundary is in the middle between these extreme values.

3. Else place tentative boundary between values that are less than the larger median (in one sample) and larger than the smaller median (in the other sample).

4. Calculate TSS in every pair.

5. Final boundary is where the TSS is the largest.

6. Output values for the optimal boundary and TSS if this boundary value is applied. 
Classification tree model for separating the four broader taxa according to our data was constructed using Statsoft Statistica Standard classification and regression trees (CART) module. ${ }^{32}$

\section{Results}

Among green macroalgae, Ulva intestinalis was the brightest species with the highest reflectance values. Ulva was followed by Monostroma balticum, Cladophora glomerata, and Chara spp. All green algal species showed a broad reflectance peak centered at $550 \mathrm{~nm}$ and reflectance trough around $675 \mathrm{~nm}$, which corresponds to the chlorophyll absorption peak [Fig. 4(a)]. Brown algal species had consistent shape in their reflectance spectra, i.e., reflectance peaks at 600 and $650 \mathrm{~nm}$ and a shoulder at $580 \mathrm{~m}$; however, the absolute reflectance values varied among species. Dictyosiphon foeniculaceus showed the highest reflectance, reaching $4.5 \%$ in the visible part of the spectrum. The reflectance values of dark brown Fucus vesiculosus reached only $1 \%$ in the visible part of the spectrum. Red algae had two clear reflectance peaks at 600 and $650 \mathrm{~nm}$. Furcellaria lumbricalis was darker than Ceramium tenuicorne
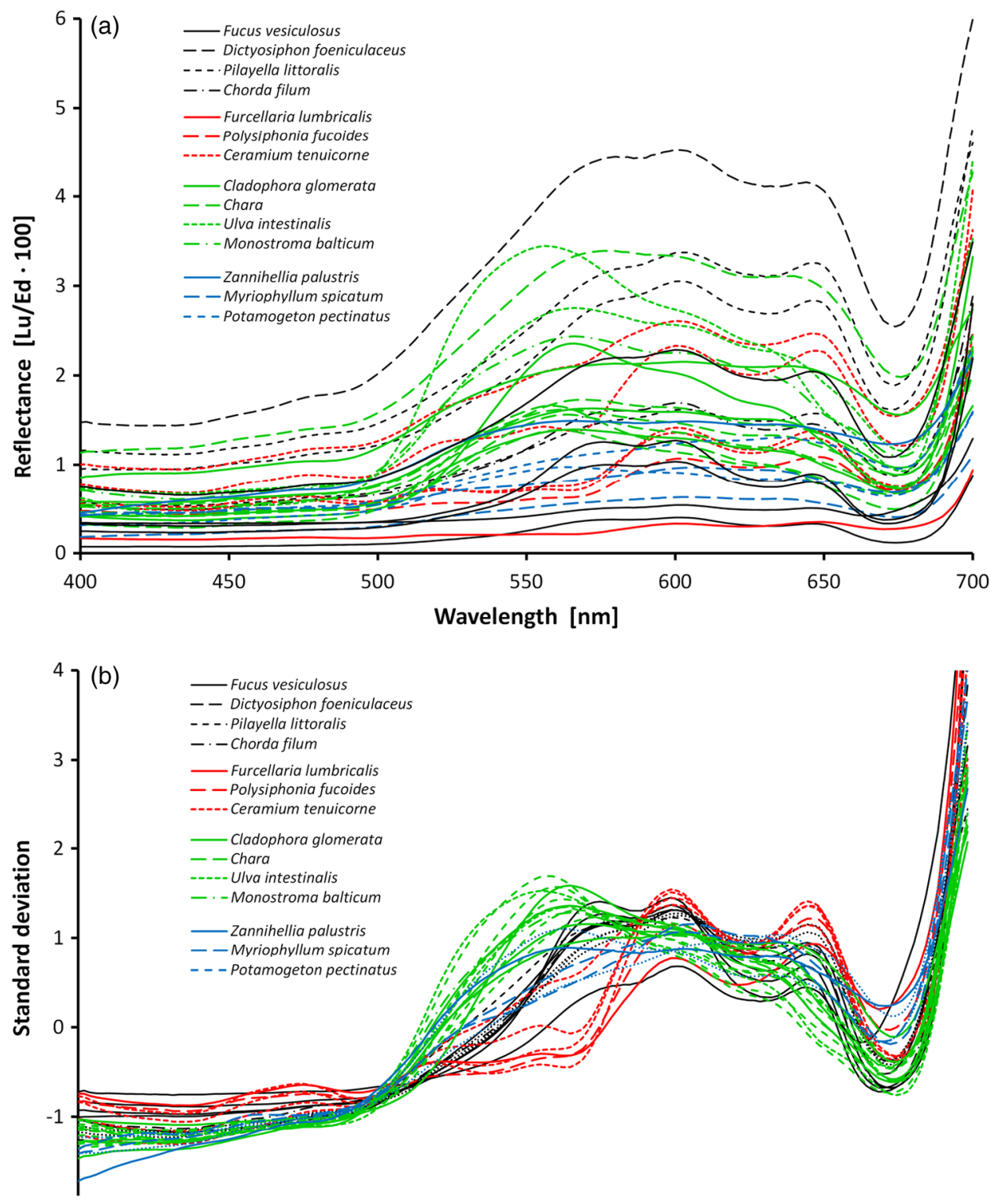

Fig. 4 The reflectance values of the studied plant individuals: (a) raw data and (b) standardized data. 


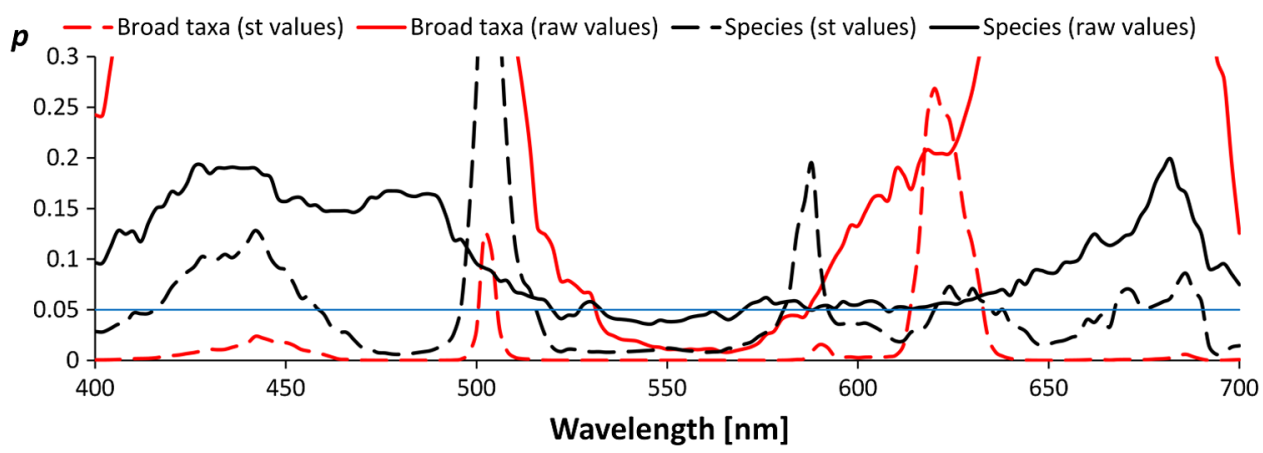

Fig. 5 Statistical significance $(p)$ according to the Kruskal-Wallis test of the difference in reflectance values between the studied groups of plant individuals. Solid lines refer to raw signatures and broken lines to standardized signatures.

and Polysiphonia fucoides, showing the lowest reflectance value throughout the entire spectrum of the red algae. Higher plant species had no specific spectral features of raw reflectances but a high reflectivity over a broad wavelength range (550 to $640 \mathrm{~nm}$ ). However, a standardization of the reflectance spectra resulted in relative high reflectances at $675 \mathrm{~nm}$.

The raw reflectance spectra of plant individuals were largely overlapping and did not enable a reliable distinction of species and larger taxonomic groups [Fig. 4(a)]. The standardization led to considerable improvement, first of all in the distinctness of green algae compared to the group of brown and red algae [Fig. 4(b)]. The green algae had higher standardized reflectance values in the spectral range of 510 to $582 \mathrm{~nm}$, which corresponds approximately to the visible green light. In most other spectral regions, the reflectance of red and brown algae exceeded the values of green algae (recall that the mean of a standardized sample is always equal to zero).

The results of Kruskal-Wallis tests also indicated that difference in the distribution of standardized reflectance values of a particular spectral interval between broad taxonomic groups is statistically significant $(p<0.05)$ in most spectral intervals, while the raw values differ significantly only within a narrow spectral range between 530 and $580 \mathrm{~nm}$. The best indicative spectral range was observed between 530 and $570 \mathrm{~nm}$ if both species and larger taxonomic units were considered. In general, difference between broad taxa was more significant than that of the studied species (Fig. 5).

Statistically significant, i.e., reliably not random, distinction between the major taxonomic groups in our data is possible at certain spectral ranges only (Fig. 6). Distinction values in standardized reflectance spectra were found even for the generally similar red and brown algae. According to our sample, a classification result, which is significantly better than expected from random decisions, is possible at 558 to $582 \mathrm{~nm}$. On average, the wavelength intervals at 470 to 492,520 to 582,646 to 658 , and 670 to 680 seem to be most indicative to distinguish broader taxonomic groups of macrophytes, although the distinction is perfect only in case of some intervals and between some groups, e.g., green and brown algae at 530 to $560 \mathrm{~nm}$.

Although the differences between distribution spectral values are mostly statistical and not perfect, there still exist a set of rules enabling perfect separation of broad taxonomic groups in our sample (Fig. 7). Variability outside the study sample is expected to be much larger.

\section{Discussion}

The current paper is the first comprehensive investigation on the measured reflectance spectra of the key macrophyte species in the Baltic Sea. These spectra can now serve as key inputs to the spectral library approach in order to map the spatial and temporal patterns of coastal macrovegetation in the Baltic Sea range. Although the measurements showed some clear-cut differences between some macrophyte species, many species had still very similar reflectance values.

We also demonstrate a methodology that allows a statistically significant separation of spectral signatures of different macrophyte species and broader taxonomic groups. In remote sensing, 

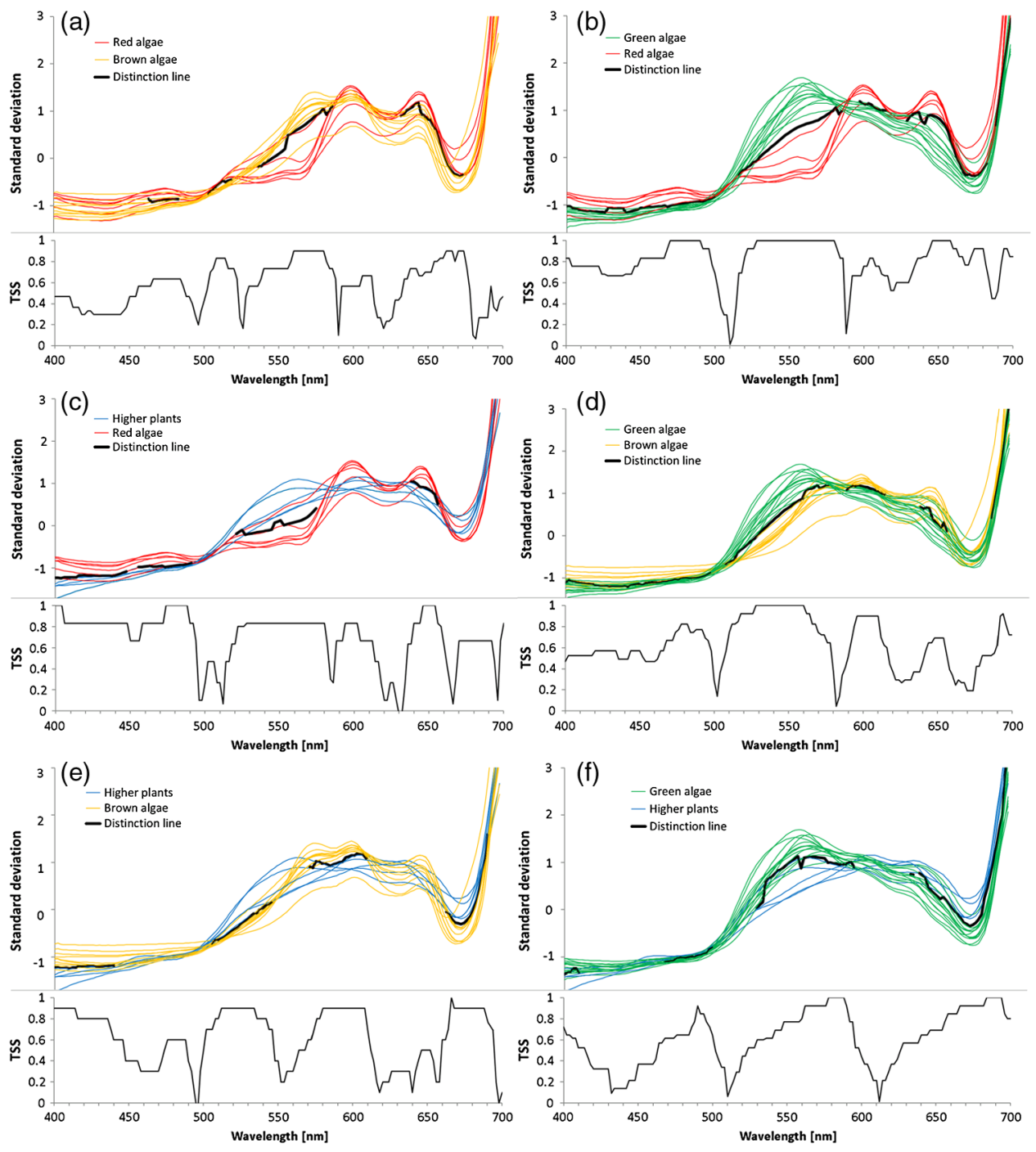

Fig. 6 Statistically significant distinction lines (thick black line) between the standardized signatures of broad taxonomic units of benthic macrophytes (above) and the true skill statistic (TSS) (below) when imposing the distinction values upon the studied sample. TSS $=1$ means perfect distinction in the study sample. Distinction line is depicted in spectral regions where the classes differ significantly according to the U-test.

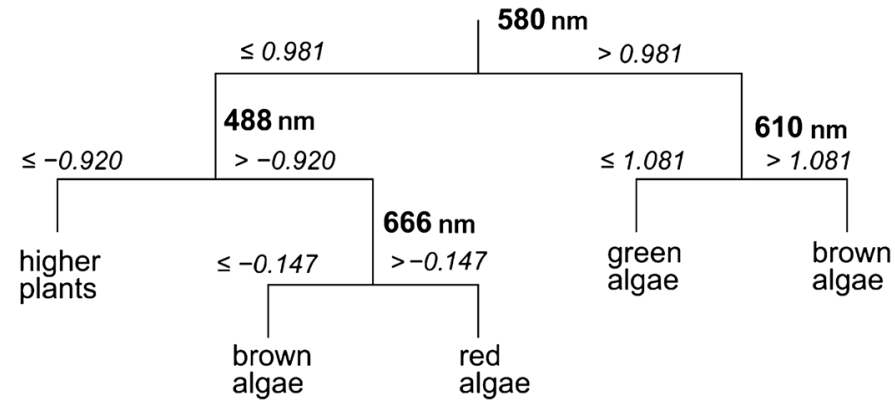

Fig. 7 Classification tree for separating broad taxonomic units of benthic macrophytes using standardized spectral values. Bold numbers mark wavelength in nanometers, and critical values for decisions are in italics. 
a spectrum of macrophyte species is often defined as a static object, i.e., the values are averaged over space and time. ${ }^{23-25}$ However, in nature, there exists a considerable variation in the composition and quantity of pigments within species induced by seasonality in light conditions, nutrient availability, exposure to waves, just to name a few (e.g., Ref. 4). Thus, it becomes rewarding and ecologically meaningful to quantify spatiotemporal variability in reflectance within species/taxa and then seek statistical options for species separation taking into account all this natural variability.

Our analyses showed that the shapes of reflectance spectra of red, green, and brown macroalgae were consistent within each group due to the presence of characteristic pigments, ${ }^{8,25}$ and the separation of these broad groups of algae by a shape of their reflectance spectra was possible. Specifically, green algae had high reflectance in the green part of the spectrum from 500 to $650 \mathrm{~nm}$ with the highest reflectance centered at $550 \mathrm{~nm}$. Characteristic green algal pigmentschlorophyll a, chlorophyll $\mathrm{b}$, and $\beta$-carotene - absorb strongly in the blue and red part of the spectrum. The presence of those absorbing pigments provokes low values in the bands from 400 to $500 \mathrm{~nm}$ as well as from 650 to $680 \mathrm{~nm}$. Chlorophyll a has absorption peaks at $\sim 435$ and $675 \mathrm{~nm},{ }^{38}$ chlorophyll $\mathrm{b}$ absorbs at $\sim 480$ and $650 \mathrm{~nm}$ (Ref. 27), and $\beta$-carotene at $\sim 425$, 451 , and $483 \mathrm{~nm} \cdot{ }^{39,40}$

The brown and red macroalgae had distinctly different signatures from one another and from the green algae. Once again, a distinct absorption maximum near $675 \mathrm{~nm}$ is conditioned by chlorophyll a absorption. Compared to green algae, the maximum reflectance values for brown macroalgae were located at the 570- to $650-\mathrm{nm}$ wavelengths. Brown algae showed enhanced absorption at the 500- to 550-nm spectral region due to fucoxanthin absorption. ${ }^{41}$ Another characteristic pigment for brown algae is chlorophyll c, which absorbs around 460 and $633 \mathrm{~nm}^{28}$ The shape of the brown algae reflectance spectra is analogous to other brown algae and many corals (containing symbiotic brown algae) measured in different parts of the world. ${ }^{17,25}$ The brown algae in the Baltic Sea showed broad reflectance peaks at 570,600 , and $650 \mathrm{~nm}$ corresponding to previous measurements in the world seas. ${ }^{6,7,9,12,42}$

Red algae were discernible from other algal groups by the presence of a dip in reflectance at $570 \mathrm{~nm} .{ }^{10}$ In addition to chlorophyll a and carotenoids, the characteristic pigment in red algae is phycoerythrin. ${ }^{38}$ Characteristic chlorophyll a absorption maxima were seen at 435 and $675 \mathrm{~nm}$ just as in case of green and brown macroalgae. Low reflectance values appearing in shorter wavelengths from 400 to $500 \mathrm{~nm}$ were conditioned by pigments $\beta$-carotene and $\alpha$-carotene. ${ }^{43}$ Phycoerythrin absorbs strongly in the middle of the visible spectrum with absorption peaks near 495,540 , and $565 \mathrm{~nm}$, depressing reflectance values in the green part of the spectrum and is, thus, almost complementary to chlorophyll in its absorption. ${ }^{38}$ The presence of chlorophyll $\mathrm{c}$ was also detectable by a small shoulder near $630 \mathrm{~nm} .{ }^{43}$ The red algae had a common double-peak pattern around 600 and $650 \mathrm{~nm}$ in their reflectance spectra, all this resembling the studies performed in other parts of the world. . $^{6,7,12,42}$

When raw reflectance values were considered, the variability within each broad taxonomic group was large and a statistical separation even among the broad macrophyte taxa was difficult. This is because the shapes of reflectance spectra of macrophyte species and taxa highly resemble each other due to the similar pigment content and overlapping absorption features of biochemical constituents. Standardized spectra partly resolved the issue; however, the separation of species still posed a great challenge. Nevertheless, a standardization of reflectance spectra was useful as it reduced noise due to natural variability of the pigment composition of macrophytes.

Statistical discrimination models used in image preprocessing (both parametric and nonparametric) need many samples in order to be trained and evaluated. However, the collection of large numbers of samples is not normally feasible, and thereby, the traditional image-based analyses do not yield to accurate discrimination models. On the other hand, the spectral library approach requires much smaller data sets and, in case of availability of high-quality atmospheric correction, the method allows an efficient mapping of benthic macrophyte communities over a large spatiotemporal range. Nevertheless, the existing spectral libraries often consist of averaged reflectance values, ignoring spectral variability among individual and taxa. In order to quantify ranges of variability, however, more empirical data are needed. Instead of providing just average species-specific reflectances, the raw values (i.e., separate measurements of each individual) are 
of utmost importance. When such information is available, it becomes rewarding to seek the optimal separating boundary between the taxa based on their statistical separation. Then, this information is used to define a set of rules enabling perfect separation of the studied taxa. Those rules represent the distinct parts of reflectance spectra where the overlap between the taxa is statistically the smallest.

In the proposed method, the original observed spectra are standardized by subtracting the mean of the spectral signature from spectral values and dividing the result by the standard deviation of values within the spectrum of a plant individual. Then, the TSS is applied as a decision basis to find the optimal separating boundary between the taxa, assuming that the best separating boundary between the taxa should be between medians of the values of one and another sample. The boundary can separate two samples either perfectly or statistically. The statistical separation can be significant or nonsignificant according to a chance of Type 1 statistical error bound with the analysis.

Unfortunately, the optimal boundaries between all possible pairs of taxa are not easy to be used for determination of a taxon from a remote sensing data. For recognition of categories, we need rules on how to use similarity, separating values, or any other decision criteria. The option to use similarity-based or case-based reasoning is effective, first of all, if the cases are complicated, the number of variables is large, different types of variables are included, and the number of cases is enormous and continuously increasing. ${ }^{44,45}$ For the present simpler case, we preferred building a hierarchical set of rules as a CART model for recognizing the taxa from remote sensing spectra. Such a classification tree enabled a perfect separation of the broad taxa in our data. The CART algorithm has been widely used to obtain an adequate set of rules allowing the separation of various end-members. ${ }^{46,47}$ Similarly, in our study, we extracted the most rewarding features for the discrimination of the studied macrophyte taxa. The key idea behind the method is that it is difficult to separate taxa by relying only on one classifier computed at a single wavelength. In addition, the CART analysis reduces the number of statistically significant bands selected by the Kruskal-Wallis test and by the Mann-Whitney $U$ test to fewer bands that could optimally discriminate the macrophyte taxa under concern. It is still useful to preselect and include only these spectral ranges where the separation between the taxa is significant according to the statistical tests, since the CART-based methods may be quite sensitive to data noise. ${ }^{48}$

We are fully aware that the current database consists of too few estimates at the species level. Nevertheless, the presented methodology allows establishment of the robust criteria in order to separate (at least some) macrophyte species in the Baltic Sea range if one increases the number of macroalgal individuals used in the training data set and if the distinct spectral features used to draw the borderline among species are maximized. Specifically, with an increasing number of rules, the probability of discriminating macrophyte species notably increases. This result encourages further evaluation of the methodology over a larger number of species.

In simple environments, including the Baltic Sea basin, macrophyte communities consist of limited numbers of species, and each broad taxon (e.g., green, brown, and red algae) is often represented by single species. ${ }^{13,49}$ In such habitats, it is already satisfying to separate only broad taxonomic groups in order to recapture the spatial distribution of coastal macrophyte communities. However, in more complex environments where biodiversity is higher and each species is characterized by a large natural within-species variability in reflectance spectra either due to genetic variation, seasonal cycles, or environmental conditions, ${ }^{43,50}$ mapping the macrophyte communities at the species level may be impossible. To conclude, the potential of the spectral library approach depends, on one hand, on the representativeness of training data set and, on another hand, on the habitat complexity and associated biodiversity. The question remains, still, how to discern species from multispecies assemblages using the spectral library classification approach. In such complex habitats, macrophytes do not grow as monospecific stand but occur in mixtures. The mixed assemblages are likely characterized by reflectances that are not necessarily the sums of the reflectance spectra of individual species. Therefore, we need to evaluate the validity of spectral standardization in future work by focusing on the reflectance spectra of mixed assemblages. 


\section{Acknowledgments}

This work was funded by Institutional Research Funding IUT2-16 and IUT02-20 of the Estonian Research Council, the Estonian Target Financing project SF0180009s11, and the project "The status of marine biodiversity and its potential futures in the Estonian coastal sea" No. 3.2.0801.11-0029 of Environmental Protection and Technology Programme of European Regional Fund. Collection of the data has been carried out in the frame of the EU Interreg IVA Central Baltic Program project HISPARES and Estonian Science Foundation grant 8576. We are also grateful to Merli Pärnoja, Kaire Kaljurand, Tiia Möller, and Greta Reisalu for help in field works.

\section{References}

1. S. J. Ormerod and A. R. Watkinson, "Large-scale ecology and hydrology: an introductory perspective from the editors of the Journal of Applied Ecology," J. Appl. Ecol. 37(S1), 1-5 (2000), http://dx.doi.org/10.1046/j.1365-2664.2000.00560.x.

2. D. Urban et al., "Extending community ecology to landscape," Ecoscience 9(2), 200-202 (2002).

3. P. J. Mumby et al., "The cost-effectiveness of remote sensing for tropical coastal resources assessment and management,' J. Environ. Manage. 55(3), 157-166 (1999), http://dx.doi .org/10.1006/jema.1998.0255.

4. J. Kotta et al., "Predicting species cover of marine macrophyte and invertebrate species combining hyperspectral remote sensing, machine learning and regression techniques,' PlosOne 8(6), e63946 (2013), http://dx.doi.org/10.1371/journal.pone.0063946.

5. T. M. Lillesand, R. W. Kiefer, and J. W. Chipman, Remote Sensing and Image Interpretation, 6th ed., John Wiley \& Sons, New York (2007).

6. S. Maritorena, A. Morel, and B. Gentili, "Diffuse reflectance of oceanic shallow waters: influence of water depth and bottom albedo," Limnol. Oceanogr. 39(7), 1689-1703 (1994), http://dx.doi.org/10.4319/lo.1994.39.7.1689.

7. K. S. Beach, H. B. Borgeas, and C. M. Smith, "Ecophysiological implications of the measurement of transmittance and reflectance of tropical macroalgae," Phycologia 45(4), 450 457 (2006), http://dx.doi.org/10.2216/05-30.1.

8. E. Vahtmäe et al., "Feasibility of hyperspectral remote sensing for mapping benthic macroalgal cover in turbid coastal waters - a Baltic Sea case study," Remote Sens. Environ. 101(3), 342-351 (2006), http://dx.doi.org/10.1016/j.rse.2006.01.009.

9. N. Oppelt et al., "Hyperspectral classification approaches for intertidal macroalgae habitat mapping: a case study in Heligoland," Opt. Eng. 51(11), 111703 (2012), http://dx.doi.org/ 10.1117/1.OE.51.11.111703.

10. J. D. Hedley and P. J. Mumby, "Biological and remote sensing perspectives of pigmentation in coral reef organisms," Adv. Mar. Biol. 43, 277-317 (2002), http://dx.doi.org/10.1016/ S0065-2881(02)43006-4.

11. T. Kutser, I. Miller, and D. L. B. Jupp, "Mapping coral reef benthic habitat with a hyperspectral space borne sensor," presented at Proc. of Ocean Optics XVI, 18-22 November 2002, Office of Naval Research, Santa Fe, NM (2002).

12. T. Kutser, I. Miller, and D. L. B. Jupp, "Mapping coral reef benthic substrates using hyperspectral space-borne images and spectral libraries," Estuar. Coast. Shelf Sci. 70(3), 449-460 (2006), http://dx.doi.org/10.1016/j.ecss.2006.06.026.

13. C. D. Mobley et al., "Interpretation of hyperspectral remote-sensing imagery by spectrum matching and look-up tables," Appl. Opt. 44(17), 3576-3592 (2005), http://dx.doi.org/10 1364/AO.44.003576.

14. E. M. Louchard et al., "Optical remote sensing of benthic habitats and bathymetry in coastal environments at Lee Stocking Island, Bahamas: a comparative spectral classification approach," Limnol. Oceanogr. 48(1), 511-521 (2003), http://dx.doi.org/10.4319/lo.2003 .48.1_part_2.0511.

15. J. C. Price, "How unique are spectral signatures?," Remote Sens. Environ. 49(3), 181-186 (1994), http://dx.doi.org/10.1016/0034-4257(94)90013-2. 
16. C. D. Clark et al., "Spectral discrimination of coral mortality states following a severe bleaching event," Int. J. Remote Sens. 21(11), 2321-2327 (2000), http://dx.doi.org/10 .1080/01431160050029602.

17. E. J. Hochberg, M. J. Atkinson, and S. Andrefouet, "Spectral reflectance of coral bottomtype worldwide and implications for coral reef remote sensing," Remote Sens. Environ. 85(2), 159-173 (2003), http://dx.doi.org/10.1016/S0034-4257(02)00201-8.

18. A. Thorhaug, A. D. Richardson, and G. P. Berlyn, "Spectral reflectance of the seagrasses: Thalassia testudinum, Halodule wrightii, Syringodium filiforme and five marine algae," Int. J. Remote Sens. 28(7), 1487-1501 (2007), http://dx.doi.org/10.1080/01431160600954662.

19. J. Ramus, "Seaweed anatomy and photosynthetic performance: the ecological significance of light guides, heterogenous absorption and multiple scatter," J. Phycol. 14(3), 352-362 (1978), http://dx.doi.org/10.1111/jpy.1978.14.issue-3.

20. T. C. Vogelmann and L. O. Björn, "Plants as light traps," Physiol. Plant. 68(4), 704-708 (1986), http://dx.doi.org/10.1111/ppl.1986.68.issue-4.

21. G. Hannach, "Spectral light absorption by intact blades of Porphyra abbottae (Rhodophyta): effects of environmental factors in culture," J. Phycol. 25(3), 522-529 (1989), http://dx.doi .org/10.1111/jpy.1989.25.issue-3.

22. S. K. Fyfe, "Spatial and temporal variation in spectral reflectance: are seagrass species spectrally distinct?," Limnol. Oceanogr. 48(1), 464-479 (2003), http://dx.doi.org/10.4319/lo .2003.48.1_part_2.0464.

23. S. Andrefouet et al., "Change detection in shallow coral reef environments using Landsat 7 ETM+ data," Remote Sens. Environ. 78(1-2), 150-162 (2001), http://dx.doi.org/10.1016/ S0034-4257(01)00256-5.

24. S. Andrefouet et al., "Use of in situ and airborne reflectance for scaling-up spectral discrimination of coral reef macroalgae from species to communities," Mar. Ecol. Prog. Ser. 283, 161-177 (2004), http://dx.doi.org/10.3354/meps283161.

25. T. Kutser, A. Dekker, and W. Skirving, "Modeling spectral discrimination of Great Barrier Reef benthic communities by remote sensing instruments," Limnol. Oceanogr. 48(1), 497510 (2003), http://dx.doi.org/10.4319/lo.2003.48.1_part_2.0497.

26. M. Darecki and D. Stramski, "An evaluation of MODIS and SeaWiFS bio-optical algorithms in the Baltic Sea," Remote Sens. Environ. 89, 326-350 (2004), http://dx.doi.org/ 10.1016/j.rse.2003.10.012.

27. HELCOM, "Checklist of Baltic Sea Macro-species," in Baltic Sea Environment Proceedings, 2012, Vol. 130, http://helcom.fi/Lists/Publications/BSEP130.pdf (21 April 2014).

28. K. S. Beach et al., "In vivo absorbance spectra and the ecophysiology of reef macroalgae," Coral Reefs 16, 21-28 (1997), http://dx.doi.org/10.1007/s003380050055.

29. R. M. Pope and E. S. Fry, "Absorption spectrum (380-700 nm) of pure water, II, integrating cavity measurements," Appl. Opt. 36(33), 8710-8723 (1997), http://dx.doi.org/10.1364/AO .36 .008710 .

30. R. P. Armitage, R. E. Weaver, and M. Kent, "Remote sensing of semi-natural upland vegetation: the relationship between species composition, and spectral response," in Vegetation Mapping: From Patch to Planet, R. Alexander and A. C. Millington, Eds., pp. 83-102, John Wiley \& Sons, England (2000).

31. H. Nagendra, "Using remote sensing to assess biodiversity," Int. J. Remote Sens. 22(12), 2377-2400 (2001), http://dx.doi.org/10.1080/01431160117096.

32. StatSoft Inc., Electronic Statistics Textbook, 2013, http://www.statsoft.com/textbook/ (15 March 2014).

33. W. H. Kruskal and W. A. Wallis, "Use of ranks in one-criterion variance analysis," J. Am. Stat. Assoc. 47(260), 583-621 (1952), http://dx.doi.org/10.1080/01621459.1952 .10483441 .

34. K. Remm and T. Kelviste, "An online calculator for spatial data and its applications," Comput. Ecol. Softw. 4(1), 22-34 (2014).

35. A. W. Hanssen and W. J. A. Kuipers, "On the relationship between frequency of rain and various meteorological parameters," Mededelingen van de Verhandlungen 81, 2-15 (1965). 
36. J. M. Pherson, W. Jetz, and D. J. Rogers, "The effects of species' range sizes on the accuracy of distribution models: ecological phenomenon or statistical artefact?," J. Appl. Ecol. 41(5), 811-823 (2004), http://dx.doi.org/10.1111/jpe.2004.41.issue-5.

37. O. Allouche, A. Tsoar, and R. Kadmon, "Assessing the accuracy of species distribution models: prevalence, kappa and the true skill statistic (TSS)," J. Appl. Ecol. 43(6), 1223-1232 (2006), http://dx.doi.org/10.1111/jpe.2006.43.issue-6.

38. F. T. Haxo and L. R. Blinks, "Photosynhetic action spectra of marine algae," J. Gen. Physiol. 33(4), 389-422 (1950), http://dx.doi.org/10.1085/jgp.33.4.389.

39. P. S. Nobel, Physicochemical and Environmental Plant Physiology, 4th ed., Elsevier Inc., Oxford, UK (2009).

40. F. P. Zscheile et al., "The preparation and absorption spectra of five pure carotenoid pigments," Plant Physiol. 17(3), 331-346 (1942), http://dx.doi.org/10.1104/pp.17.3.331.

41. J. M. Anderson and J. Barrett, "Chlorophyll-protein complexes of brown algae: P700 reaction centre and light harvesting complexes," in Chlorophyll Organization and Energy Transfer in Photosynthesis, G. E. W. Wolstenholme and D. W. Fitzsimons, Eds., pp. 81-104, John Wiley \& Sons, Chichester, UK (1979).

42. P. R. C. Fearns et al., "Shallow water substrate mapping using hyperspectral remote sensing," Cont. Shelf Res. 31(12), 1249-1259 (2011), http://dx.doi.org/10.1016/j.csr.2011.04 .005 .

43. G. Casal et al., "Assessment of the hyperspectral sensor casi-2 for macroalgal discrimination on the Ría de Vigo coast (NW Spain) using field spectroscopy and modelled spectral libraries," Cont. Shelf Res. 55(1), 129-140 (2013), http://dx.doi.org/10.1016/j.csr.2013.01.010.

44. D. W. Aha, "The omnipresence of case-based reasoning in science and application," Knowl.Based Syst. 11(5-6), 261-273 (1998), http://dx.doi.org/10.1016/S0950-7051(98)00066-5.

45. K. Remm, "Case-based predictions for species and habitat mapping," Ecol. Model. 177(34), 259-281 (2004), http://dx.doi.org/10.1016/j.ecolmodel.2004.03.004.

46. L. Yang, C. Huang, and C. G. Homer, "An approach for mapping large-area impervious surfaces: synergistic use of Landsat-7 ETM+ and high spatial resolution imagery," Can. J. Remote Sens. 29(2), 230-240 (2003), http://dx.doi.org/10.5589/m02-098.

47. L. Jiang, M. Liao, and H. Lin, "Synergistic use of optical and InSAR data for urban impervious surface mapping: a case study in Hong Kong," Int. J. Remote Sens. 30(11), 27812796 (2009), http://dx.doi.org/10.1080/01431160802555838.

48. J. Han and M. Kamber, Data Mining Concepts and Techniques, China Machine Press, Beijing (2007).

49. J. Kotta et al., Gulf of Riga and Pärnu Bay, in Ecology of Baltic Coastal Waters, U. Schiewer, Ed., pp. 217-243, Springer Ecological Studies, Berlin, Heidleberg (2008).

50. S. P. Dawson and W. C. Dennison, "Effects of ultraviolet and photosynthetically active radiation on five seagrass species," Mar. Biol. 125(4), 629-638 (1996), http://dx.doi .org/10.1007/BF00349244.

Jonne Kotta is a lead research scientist at the Estonian Marine Institute. He received his $\mathrm{PhD}$ in biology from the University of Tartu in 2000 . He is the author of more than 100 journal papers and has written over 20 book chapters. He studies structure and functioning of coastal ecosystems. He is the editor of chief in the Estonian Journal of Ecology and an editor of Hydrobiologia and the Scientific World Journal.

Biographies of the other authors are not available. 